\title{
On the morphological evolution of restored banks: Case study of the Meuse river
}

\author{
Gonzalo Duró $^{1, *}$, Alessandra Crosato ${ }^{1,2}$, Maarten Kleinhans ${ }^{3}$, and Wim Uijttewaal ${ }^{1}$ \\ 1 Department of Hydraulic Engineering, Delft University of Technology, 2628CN Delft, the \\ Netherlands \\ ${ }^{2}$ Department of Water Engineering, IHE-Delft, 2601DA Delft, the Netherlands \\ ${ }^{3}$ Department of Physical Geography, Utrecht University, 3508TC Utrecht, the Netherlands
}

\begin{abstract}
In recent years, many riverbanks in Europe had their protections removed to reactivate natural erosion processes and improve riparian habitats. Yet, other river functions may be affected, such as navigation and flood conveyance. The quantification and prediction of erosion rates and volumes is then relevant to manage and control the integrity of all river functions. This work studies the morphological evolution of riverbanks along two restored reaches of the Meuse River in the Netherlands, which are taken as case studies. This river is an important navigation route and for this its water level is strongly regulated with weirs. Through aerial photographs and two airborne LIDAR surveys, we analysed the evolution over nine years of restoration and reconstructed the topography along $2.2 \mathrm{~km}$. of banks. An extraordinary low-water level after a ship accident provided the opportunity to observe and measure the bank toe. The banks show a terrace of erosion close to the normally regulated water level, highly irregular erosion rates up to $7 \mathrm{~m} /$ year, embayments evolving with upstream and downstream shifts, and sub-reaches with uniform erosion. Probable causes of erosion include ship-waves, high water flows and water level fluctuations. Distinct patterns might be explained by the presence of riparian trees and soil strata of different compositions. These intriguing case studies will continue to be studied to disentangle the role of different erosion drivers, predict erosion magnitudes and establish whether bank erosion will stop or continue in the future.
\end{abstract}

\section{Introduction}

River restoration has been systematically applied in Europe to improve the ecological quality of river systems since the EU Water Framework Directive 2000/60/EC (WFD, http://data.europa.eu/eli/dir/2000/60/oj). The approach is based on improving the river hydromorphology through measures such as removing bank protections, creating shallow banks and allowing bar formation. Within the river, riparian areas have shown a relatively fast recovery after restoration [1-3]. Particularly, near-bank areas exhibited larger habitat diversity than main channels [e.g., 2], which highlights the relevance of riverbanks to

\footnotetext{
* Corresponding author: g.duro@tudelft.nl
} 
improve the ecology of these corridors for flora and fauna, especially in natural conditions [4].

Highly anthropised rivers usually require a compromise among their multiple functions, a challenge driven by conflicting interests, within which the ecological value of naturally eroding riverbanks is no exception. The Meuse River, for instance, has had several kilometres of riverbanks restored for ecological reasons, which are now allowed to erode. At the same time, this river is a waterway that needs to convey peak floods and requires minimum water levels to allow for commercial shipping, both of which might potentially be hindered by excessive sediment yield from eroding banks. It is therefore important to estimate and evaluate the magnitude and rates of erosion for river managers to comply with all river functions. Yet, the quantification and prediction of erosion rates and volumes is a challenging endeavour [5] and long-term development and equilibrium state (if any) of these restored reaches is currently uncertain.

Herein, we present the morphological evolution of two case studies and quantify the eroded volumes after up to nine years to characterize the erosion of restored banks in navigable rivers, and perform a preliminary analysis on potential drivers. We consider reaches of the Meuse River of approximately $1 \mathrm{~km}$ as case studies, located near the city of Boxmeer, The Netherlands. The left banks had the rip-rap protections fully removed and experienced erosion which we could measure during an extraordinary low-water level event. This was the result of a ship accident against the weir located downstream of the study reaches, on January 2017.

\section{Methods}

\subsection{Case studies on the Meuse River}

The Meuse River is a highly regulated river, with a series of weirs that keep minimum water levels, bend cut-offs, and protections that prevented banks from eroding. During the first phase of restorations after the WFD, $750 \mathrm{~m}$ of reach A (Figure 1) had the left-bank riprap removed in 2008. In 2010, the remaining $250 \mathrm{~m}$ of reach $\mathrm{A}$ and $1.2 \mathrm{~km}$ of reach $\mathrm{B}$ followed the same path (Figure 1).

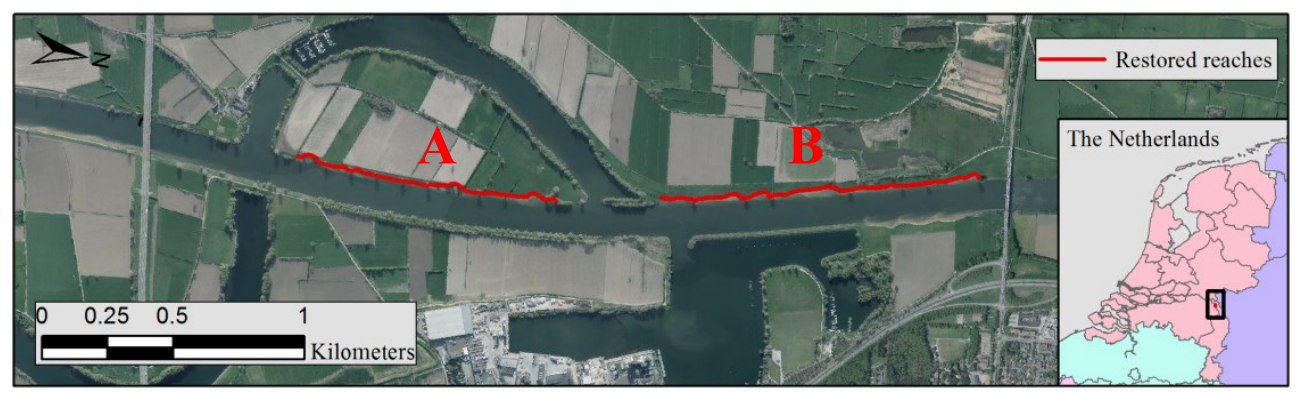

Fig. 1. Location of restored reaches under analysis

\subsection{Aerial photographs and Airborne Laser Scanning (ALS) surveys}

We made use of yearly aerial photographs to measure the planform evolution of the restored banks, i.e., the bankline migration over consecutive years. The photographs have resolutions of $0.20 \mathrm{~m}$ and $0.10 \mathrm{~m}$, for the respective periods of 2010-2012 and 2013-2017, and they were orthorectified by the provider before our deployment. We delineated in 
ArcMap the bankedge with previous knowledge of on-site features, such as stone removal footprints and terrain slopes, which were accordingly interpreted from the photograph's top perspective. Finally, the aerial photograph corresponding to 2016 was not available and thus not considered in this work.

We used two ALS surveys to quantify the erosion volumes for the period under study. The first survey was carried out during the first quarter of 2011, after the implementation of the restoration projects in 2008 and late 2010. The second survey was performed on January 2017, during an extraordinary low water level which exposed a terrace at the bank toe. Both ALS were done from an airplane at $300 \mathrm{~m}$ from the ground and generated a $0.5 \mathrm{~m}$ grid. The ALS captured the topography until the water level, which at the moment of the surveys were approximately $8.0 \mathrm{~m}$ and $6.0 \mathrm{~m}$ respectively for 2011 and 2017.

The first ALS survey required the extrapolation of bank profiles due to the initial erosion that occurred before 2011. The banks immediately after the restoration works had typical slopes of $1: 2.5$, which is similar to the design profile of the revetments previously in place, so we considered the same slope to "refill" the banks. Since a variety of erosion magnitudes occurred, we first identified whether there was a bank scarp on each profile along the reaches. For those sections with a scarp, the top edge was identified based on slope changes, and we took it as the initial point for the bank extrapolation. In those cases where the erosion was still low, the extrapolation was done at the end of the measured profile, i.e. slightly above the water level. In both cases, the profiles were extended until the terrace level on 2017, from the second ALS survey. Figure 2 shows two typical bank profiles on early 2011 with distinct erosion magnitudes and respective extensions.

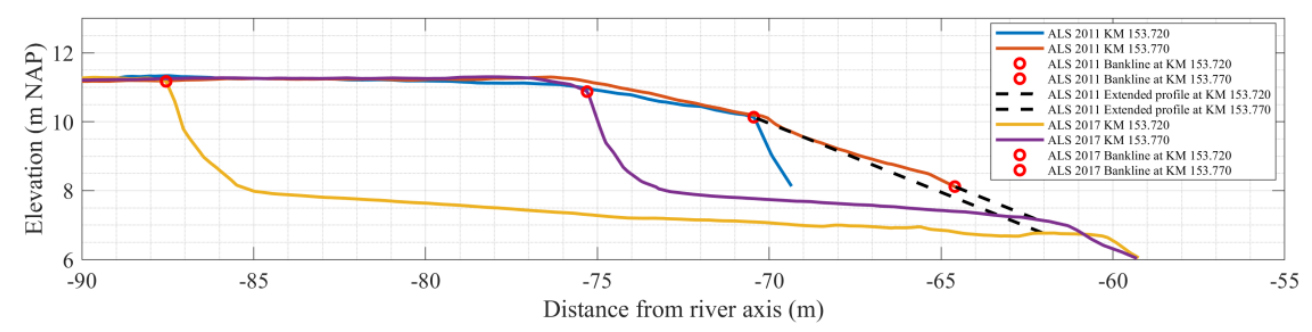

Fig. 2. Cross sections at $\mathrm{km} 153.720$ and 153.770 on 2011 , with extended profile, and 2017, with terrace at the bank toe.

In this way, the initial bank profiles after restoration were estimated and all reaches had a condition similar to the initial one. Figure 2 also presents profiles of 2017 during the low water level, which shows the terrace at the bank toe. For this survey, bank edges were also identified to limit the subtraction of the two profiles to the eroded part. The erosion volume was finally calculated every $0.5 \mathrm{~m}$ with the areas between the profiles. We performed all computations with MATLAB.

\section{Results}

The banks after seven-to-nine years of restoration present two distinct patterns in both reaches under analysis: uniform retreat and embayments (Figures 3-4). This difference is clearly evident for reach $\mathrm{A}$, which has long reaches with barely any erosion and three $\sim 30$ m deep isolated embayments (Figure 3a-b). On the other hand, reach B shows two subreaches: the first with a series of rather continuous embayments (Figure $4 \mathrm{a}$ ), and the second with a uniform type of erosion until the last $100 \mathrm{~m}$ (Figure $4 \mathrm{~b}$ ). 


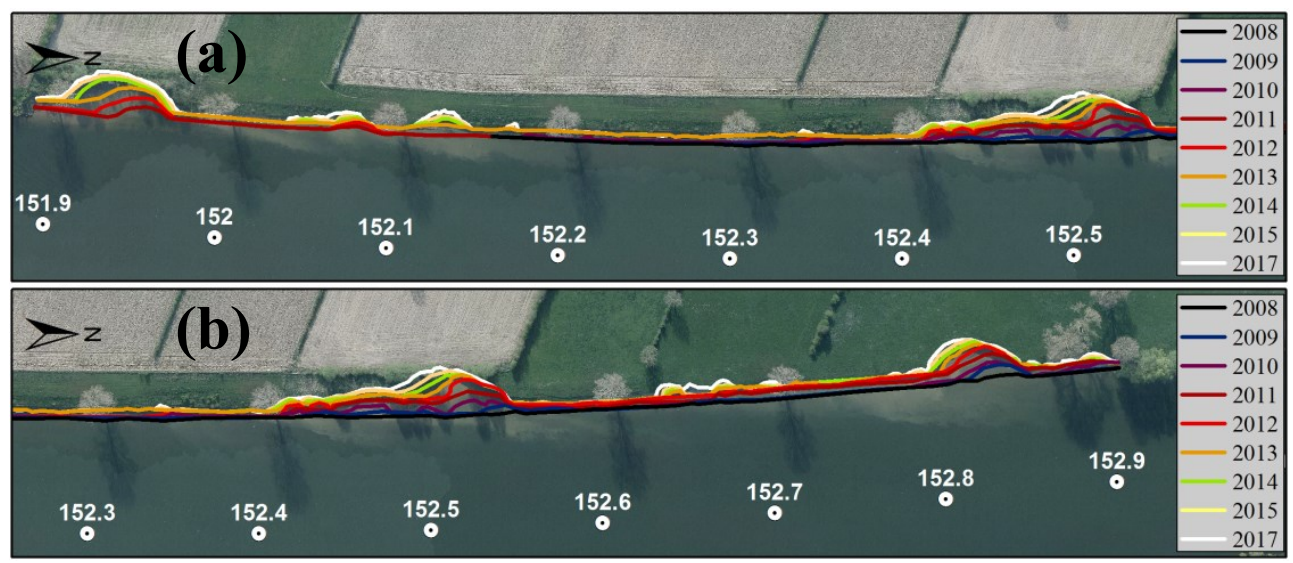

Fig. 3. Bankline migration at reach " $A$ " over 9 years for upstream (a) and downstream (b) sub-reaches
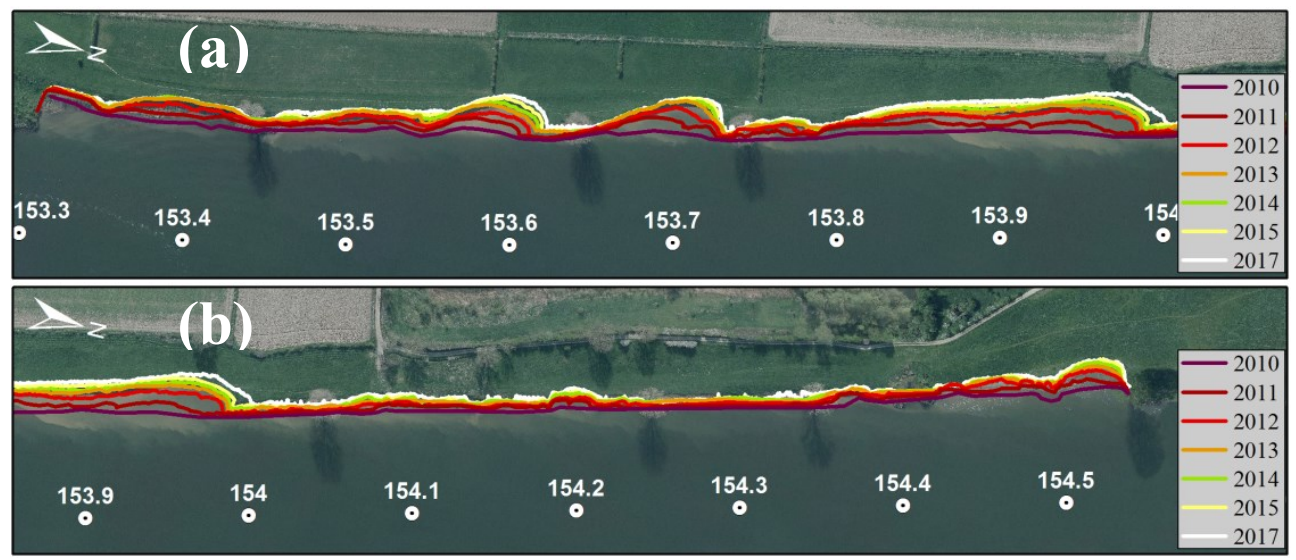

Fig. 4. Bankline migration at reach "B" over 7 years for upstream (a) and downstream (b) sub-reaches

Over the years, the banks evolved from a smooth continuous bankline into highly heterogeneous ones, with specific areas that experienced high erosion rates up to $7 \mathrm{~m} /$ year (e.g., Figure 3a, km. 153.92-153.98 between 2011 and 2012). The trend of the erosion patterns was evident 1 or 2 years after the restorations for most embayments, so the initial response of the system was then further developed in time. The temporal evolution of embayments shows some differences between reaches A and B. In the former, embayments appeared to progress with a somewhat uniform erosion rate (separation between consecutive banklines), but in the latter, the highest rates in general occurred during the first two years and then decreased over time. Finally, the embayments of reach A evolved with an upstream shift whereas those in B did it in downstream direction.

Figure 5 presents the eroded volumes per metre of river length for reaches A and B. A huge variability of sediment yield is evident in both reaches, whose maximum amplitudes are similar but frequencies differ. The minimum eroded volume per metre is located where uniform retreat occurred, with an average value of $2.5 \mathrm{~m}^{3} / \mathrm{m}$. The maximum eroded volume happened at embayments, with peak values of $36 \mathrm{~m}^{3} / \mathrm{m}$. Finally, the average for reach A was $7.6 \mathrm{~m}^{3} / \mathrm{m}$ whereas for reach B was $11.4 \mathrm{~m}^{3} / \mathrm{m}$. 

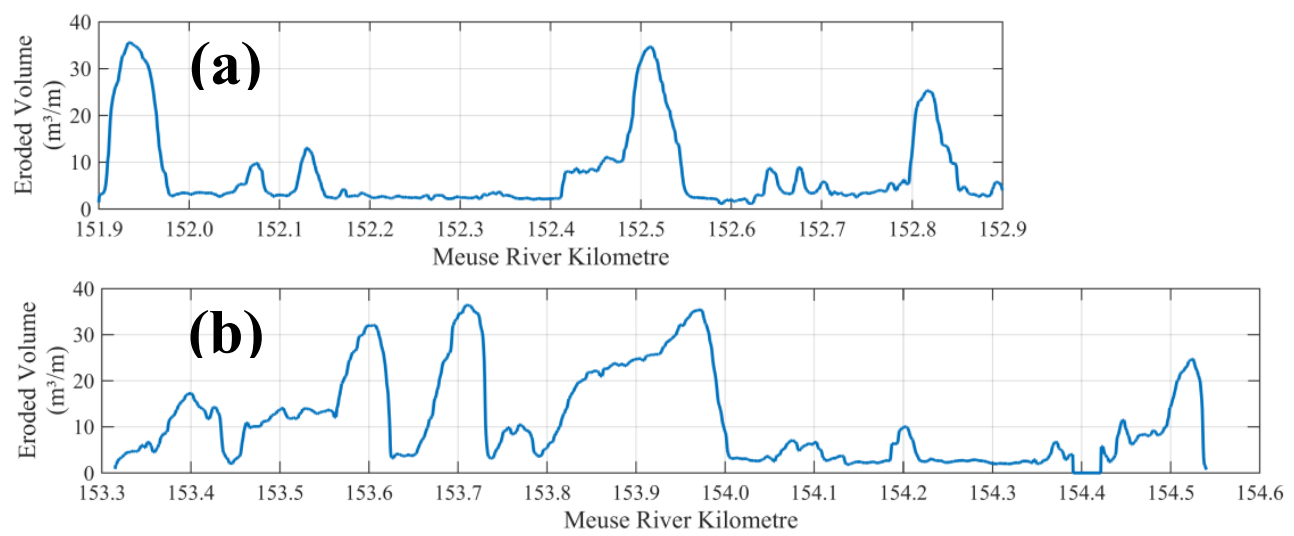

Fig. 5. Eroded volumes of reach “A” (a, top) and reach "B” (b, bottom) until January 2017

\section{Discussion}

The planform evolution of these case studies presented highly heterogeneous patterns, which several factors might explain. In the first place, potential erosion drivers include high flows that usually act during winter time, water level fluctuations inducing mass failures, and ship-induced waves which are present over the whole year.

High flows induce shear stresses in the near-bank area, and strong points along the bank line (e.g., tree roots) may induce flow separation and further downstream erosion. The length scales of complex flow structures could be investigated through detailed numerical modelling to evaluate potential feedback mechanisms of erosion during high flows. Drawdown effects after floods [6] might play a role when scarps are present (see Figure 2), but not during the initial condition after restoration with mild bank slopes. Given the latter and the fact that erosion rates at reach B were decreasing over time, it is likely that this effect is not a dominant one. Finally, ship-induced waves despite uniformly acting along banks, may act in concert with, for instance, a varying erosion resistance, which can result in a non-uniform response of the system.

Factors influencing the bank resistance may then also be playing a role. For instance, the presence of trees next to the bankline sometimes appear to create strong points of relative low retreat (e.g., Figure 3a, km. 152.1), but in other places it seems not to have influenced bank erosion rates (e.g., Figure 4a, km. 153.94, where there used to be a tree that was dislodged). In addition, bank material characteristics may change bank erosion rates [e.g., 7], which would require further investigations.

Irrespectively of the erosion magnitude, the presence of a terrace at the bank toe resulted ubiquitous. The approximate elevation of this terrace $(\sim 7-8 \mathrm{~m}$, see Figure 2$)$ is close to the regulated water level $(\sim 8 \mathrm{~m})$, where ship waves can act to erode banks [e.g., 8 ] and might explain the terrace formation. On the other hand, a weak soil stratum at the mentioned elevation could also have created it.

Despite the short period for bank erosion presented herein, the fact that the rates and magnitudes highly differ along the reaches represents a challenge for predictive tools to estimate such behaviours and consequent volumes of erosion. For instance, bank erosion models based on bend curvature and excess velocity for meandering rivers [e.g., 9] could not explain the short-term erosion at reach $\mathrm{B}$, which is straight (Figure 1). Two-dimensional models whose bank erosion modules are based on excess bank height [e.g., 10] would also present shortcomings, since the initial condition of these reaches are profiles with mild slopes, which are uniform along the reaches. Process-based models would seem to be the 
adequate alternative for predicting heterogeneous erosion, since, for instance, they may consider variations in soil composition and bank vegetation [e.g., 11], albeit still not including ship-induced erosion.

\section{Conclusion}

This work proposed to characterize the morphology of restored banks in a waterway. We described the temporal evolution of two reaches along seven-to-nine years, which presented distinct erosion patterns. Although the causes of these patterns are still unknown, we indicated hypothesis which give possible explanations. Regardless of its reasons, both reaches presented a terrace of erosion close to the minimum regulated water level.

Bank erosion rates reached $7 \mathrm{~m} /$ year with erosion volumes peaking $36 \mathrm{~m}^{3} / \mathrm{m}$ after seven years, whereas other sub-reaches presented a total sediment yield of only $2.5 \mathrm{~m}^{3} / \mathrm{m}$ after nine years. Given the highly heterogeneous nature of the bank erosion in these reaches, it is important that river managers monitor the evolution of restored banks especially during the first years, since the patterns of further erosion become apparent at an early stage and may indicate highly erodible locations to plan further management.

The prediction of highly varying erosion rates and volumes remains a challenge, and process-based models that include interacting and multiple erosion drivers appear to be necessary to approach such cases. These case studies will continue to be analysed to disentangle the role of single factors which may explain their intriguing behaviour.

\section{References}

1. M. Groll, Geomorphology (2017).

2. A. Lorenz, P. Haase, K. Januschke, A. Sundermann, D. Hering, Science of The Total Environment, 613, 1185-1195 (2018).

3. D. Hering, J. Aroviita, A. Baattrup-Pedersen, K. Brabec, T. Buijse, F. Ecke, N. Friberg, M. Gielczewski, K. Januschke, J. Köhler, B. Kupilas, A. Lorenz, S. Muhar, A. Paillex, M. Poppe, T. Schmidt, S. Schmutz, J. Vermaat, P. Verdonschot, R. Verdonschot, C. Wolter, J. Kail, J. Appl. Ecol. 52, 1518-1527 (2015).

4. J. Florsheim, J. Mount, and A. Chin, BioScience, 58(6), 519-529 (2008).

5. A. Siviglia, A. Crosato. Adv. Water Resour., 93(A), 1-3 (2016).

6. M. Rinaldi, N. Casagli, S. Dapporto, A. Gargini, Earth Surf. Process. Landf., 29, 237254, (2004).

7. K. Konsoer, B. Rhoads, E. Langendoen, J. Best, M. Ursic, J. Abad, M. Garcia, Geomorphology, 252, 80-97, (2016).

8. M. Liedermann, M. Tritthart, P. Gmeiner, M. Hinterleitner, E. Schludermann, H. Keckeis, H. Habersack, Hydrobiologia, 729(1), 17-31, (2014).

9. S. Ikeda, G. Parker, K. Sawai, J. Fluid Mech. 112, 363-377, (1981).

10. E. Mosselman, Hydrological Processes, 12(8), 1357-1370, (1998).

11. K. Klavon, G. Fox, L. Guertault, E. Langendoen, H. Enlow, R. Miller, A. Khanal, Earth Surf. Process. Landf., 42(1), 191-213, (2017). 